\title{
Sooner or later? The impact of child education on household consumption
}

\author{
Carmen Aina ${ }^{1} \cdot$ Daniela Sonedda $^{1,2}$
}

Received: 18 February 2021 / Accepted: 24 November 2021 / Published online: 13 January 2022

(c) The Author(s) 2022

\begin{abstract}
We study the impact of one more year of child's education on household (non-durable) consumption. We exploit an exogenous shock generated by a university reform in Italy in the early 2000s. We find that families responded in a way that is consistent with education as a production good. The higher child's education produced household positive, permanent income innovations. Hence, family non-durable consumption increased. Our findings suggest that education can be an insurance device against adverse permanent income shocks. The 2001 reform not only positively affected offspring's years of schooling, but it also had a positive effect to boost household consumption.
\end{abstract}

Keywords Demand for schooling · Household consumption · Human Capital

JEL Classification I21 $\cdot$ I28 $\cdot$ D10 $\cdot$ D14

\section{Introduction}

Inequalities in education could bring in societal disparities. The lack of schooling could prevent many to boost their incomes, and therefore their consumption level. Yet, its shortage unfolds an inefficient use of the economy's resources. These two arguments hail reforms to increase people's years of schooling. For decades, economists have

\begin{abstract}
We are grateful to two anonymous referees and the associate editor for suggestions and comments that helped to improve the paper. We also thank Eliana Baici, Rinaldo Brau, Marco Francesconi, Paolo Ghinetti, Fabrizio Iacone, Emanuela Marroccu, Federico Perali, Mariacristina Rossi, Martin Zagler and Claudio Zoli and audiences in seminars held at Cagliari, Leuven (LEER conference), Novara and Verona for valuable comments. We are fully responsible for any errors. We gratefully acknowledge the financial support from the University of Eastern Piedmont.
\end{abstract}

\footnotetext{
$凶$ Daniela Sonedda

daniela.sonedda@uniupo.it

1 University of Eastern Piedmont, Via Perrone 18, 28100 Novara, Italy

2 Centre for North South Economic Research (CRENoS), Cagliari, Italy
} 
been studying the impact of such reforms on the labour market outcomes. But, all these works neglect to analyse the household behaviour in response to them. These uncharted effects have welfare implications that are hard to detect when looking at the individual level outcomes. We could miss a part of the story.

Altruistic parents may change their consumption level when hit by a reform that encourages their child to take in more education. This circumstance occurs when parents internalise the impact of child years of schooling on the household's permanent income. In such a way, education proves to be an insurance device against adverse permanent income shocks. This mechanism fits into a big picture so far unresearched. The optimal choice of schooling years at the individual level could impose a sooner or later trade-off. Individuals give up some income (consumption) today to earn more income (and then consume more) in the future. Taking into account the household choice eases this trade-off.

In this paper, families are active agents in analysing the Bologna process reform. ${ }^{1}$ This reform lowered the costs of university attendance in Italy in 2001. Hence, we exploit this quasi-experimental variation to address the following questions. Do postcompulsory education choices change? Does this change affect household permanent income? If this is the case, does household (non-durable) consumption increase?

Answering these questions feeds in showing whether household consumes more when they invest in education. The extent to which household consumption varies is relevant for a comprehensive analysis of policies that generally reduce education costs and the Bologna process in particular for two reasons. First, this is a first step to assess family responses to changes in the design of the university system. Second, household consumption lifts welfare.

We start by modifying the reference model by Card (1999) to show whether and how households change their consumption in response to the reform. Our primary assumption is that families internalise the impact of child education on their permanent income. They do so because of altruism and minimise the risk of helping the child in financial distress. A vast literature focused on the wage returns of education. However, education is also a powerful device to reduce the probability of facing adverse income shocks regarding a less continuous employment carrier. The model implications are informative about the family behaviour. As described in Lazear (1977), education is a joint product, which produces potentially lifetime income gains while providing utility simultaneously. Hence, it is not clear on a priori grounds the causality process behind the relationship between education and income and then between education and consumption. Lazear (1977) finds that education is a costly production rather than a consumption good. Assume that the family takes an active role in the child schooling decision. In such a case, this choice impacts the family's lifetime income gains, and household consumption varies. We document how one more year of child schooling raises household consumption.

Despite the considerable changes entailed by the Bologna process, it received little attention from scholars. We improve upon this limited literature. Empirical evidence has almost entirely focused on its effects on key student outcomes. For instance,

\footnotetext{
1 The Bologna process, starting with Sorbonne and Bologna Declarations, sought to bring more coherence to higher education systems across Europe. It created the European Higher Education Area (EHEA) to promote student and staff mobility, to make higher education more inclusive and accessible (see Sect. 2.2).
} 
Bondonio and Berton (2018) analyse individual enrolment, retention rates, and ontime graduation. After the reform, they find that first-year student enrolments are between 14.5 and 17.3 percentage points higher. A deteriorated retention and ontime graduation rates did not accompany these outcomes. Cardoso et al. (2008) study the impact on individual enrolment rates; Cappellari and Lucifora (2009) Di Pietro and Cutillo (2008) D'Hombres (2007) on dropout rates; Hahm and Kluve (2019) on graduation rates, study duration and final grades. No studies analyse its hidden consequences related to the household's behaviour. This exercise is the first step in this direction.

Estimating household consumption responses to a child's years of schooling poses one main identification challenge: the decision to invest in the child's education is endogenous. Household consumption levels vary across families, possibly due to differences in unobservable, time-varying and time-invariant characteristics that can also influence educational choices. The features of the 2001 reform allow us to address this identification issue. Italy enacted it suddenly, leaving little room for anticipatory effects. ${ }^{2}$ The new law introduced a two-tier university degree (three-year course degree plus an optional two-year course degree), replacing the previous one-tier undergraduate programme. The two-tier degree and the smaller number of exams with shorter courses made the university attendance less costly.

Controlling for family-specific fixed effects in a regression model that includes a dummy variable for being treated by the reform could be a way to address the endogeneity issues. This approach identifies the effect of the reform using only families observed both before and after it. Its primary disadvantage is that we have an unbalanced panel with a high attrition rate. Hence, we rely on an identification strategy at the child age/birth year cell level. The main advantage is that it makes full use of households with observations only before the reform and those observed only after it. Hence, we exploit an identification strategy based on exogenous variability across ages and birth cohorts. Our main ingredient of the exogenous treatment is the child's birth year that determines if the child reaches an age before or after introducing the reform. Then, households with a similar child age composition experienced differential shifts in child's years of schooling. We also exploit the staggering in ageing. Some cohorts are affected at some ages but not in others. This identification strategy stems from a randomised source of variation at the child level. Yet, we want to compare household outcomes. In the treated/untreated comparison between children, these children have to live in similar treated/untreated families. Another challenge adds to it. This policy generated heterogeneous changes in child years of schooling across otherwise similar individuals. More specifically, these changes depend on the age of the individuals. Marginal costs and benefits of one more year of education likely vary across ages. Ideally, we would estimate our empirical model age by age. We do not have enough observations to do that. We sort out both issues assuming a parallel age trend assumption conditional on some covariates. We control for the child's age profile using a quadratic polynomial function in age. In this way, we are identifying the counterfactual age profile in the absence of the reform. On average, households

\footnotetext{
${ }^{2}$ Italy was one of the earliest European countries to implement the Bologna process.
} 
with a child treated by the reform would have experienced the same age profile of consumption of untreated families didn't the reform take place.

We use data drawn from the Survey on Household Income and Wealth (SHIW), database of the Bank of Italy, which permits us to observe net family income, family composition, family background, family consumption and children's years of schooling. We restrict our attention to individuals aged 15 and 22 years old in 1995-2006 and living in families whose heads aged from 39 to 60 years old. We carry out the analysis at the family level. In Italy, the choice to enrol at university takes place, on average, at age 19. Usually, at that age, individuals still live with their parents. This fact is independent of individual occupational status. Italy is a country characterised by "latest (with respect to other countries) late transition to adulthood" of the youth (Billari and Tabellini (2010); Manacorda and Moretti (2006)). For instance, for men and women born between 1966 and 1970, on average, a high-school degree is completed at age 19.2 (men) and 19.3 (women), individuals enter into the labour market at age 21.4 (men) and 24.0 (women) and leave parental home at age 27.2 (men) and 25.1 (women), (Mazzucco et al. (2007)). The late transition to adulthood was mainly an Italian phenomenon in the past. Recently, this circumstance is spreading to other countries, such as, for instance, the UK. ${ }^{3}$ However, in our model, what drives the household's behaviour is not cohabitation. Altruistic parents internalise child education's impact on their permanent income.

To conduct our analysis, we include the treatment into a control function model estimated over 1995-2006. The control function is a more general method than $I V(2 S L S)$. However, we present estimates using both methods to show that they do not differ much. We compare the consumption of differentially treated families before and after the reform. Our results document that the Bologna process reform raised the children's schooling years, particularly for those aged 18 or more. In turn, this shift-induced a positive and permanent income shock for treated families compared to the no reform scenario. Then, one more year of child education increases family non-durable consumption by $0.30 \mathrm{log}$ points. We use an administrative dataset, LoSai, to complement our analysis by presenting age profiles for treated and untreated cohorts on the employment probability and earnings per day worked. Compared to untreated individuals, treated cohorts benefit from a higher employment probability and higher earnings per day worked. Hence, the household expectations of increasing their permanent income with one more year of a child's education are rational.

Our simple model relates household consumption to child education. In the main text, we report non-durable consumption, leaving in the "Online Appendix C1.1" the findings on overall consumption level. We do so to emphasise that even if consumption increased as well, non-durable consumption raised slightly more. We interpret this finding as evidence consistent with Cappellari and Lucifora (2009)'s argument that those who benefited more from the reform are individuals coming from a household with a less advantaged family background. For these families, non-durable consumption expenditures represent a more significant fraction of the entire consumption bundle.

\footnotetext{
3 For instance, an article in The Guardian (16/11/2019) reports the $46 \%$ increase in young people aged 20-34 in UK living with parents over the last two decades.
} 
Hence, a comprehensive evaluation of the Bologna process reform requires analysing the consequences of non-durable consumption arising from household behaviour. Previous literature has focused on the behavioural responses of young individuals (see Cappellari and Lucifora 2009; Bondonio and Berton 2018; Hahm and Kluve 2019). Another strand of the literature has emphasised the household life cycle's role, rather than time-specific, credit constraint on the human capital accumulation process of the child (see for instance Cameron and Heckman 2001; Keane and Wolpin 2001; Cameron and Taber 2004; Hai and Heckman 2017). Carneiro and Ginja (2016) analyse the effect of permanent and transitory shocks to household income on parental investments in children. ${ }^{4}$ The authors find evidence that the insurance against temporary income shocks of household investments is complete, but only partial against permanent income shocks, albeit the size of the effect is negligible. Carneiro et al. (2016) develop further this issue showing that the child's educational achievements similarly respond to family income shocks as (non-durable) consumption. Under this setting, the household (non-durable) consumption and the children's educational choices are related.

Our framework allows for an exogenous shift of the household lifetime income induced by the exogenous variation of the children's years of schooling. We model this shift of the family expected permanent income shock or an expected lower probability of future adverse income shocks. Given this shift, household (non-durable) consumption increases. Therefore, we conclude that household behaviour is pivotal to assess the consequences of the Bologna process reform. Our mechanism relaxes the sooner or later trade-off, with the higher household's permanent income, consumption raises as well.

The paper's remainder proceeds as follows: Sect. 2 provides a simple theoretical framework and describes Italy's Bologna process reform. We introduce the data and the empirical model in Sects. 3 and 4, respectively. Results are discussed in Sect. 5 that precedes our conclusions in Sect. 6.

\section{Framework}

\subsection{The setting}

Several studies support both theoretically and empirically the argument that education causes various non-market outcomes, including consumption (Grossman (2006)). For instance, an increase in schooling years raises the individual demand for items with positive income elasticities (see Grossman (2006) for an extensive review). Michael (1972) and Michael (1973) show that schooling positively impacts luxuries but negatively on necessities, while there should be no effect on commodities with a unitary income elasticity. When the analysis is limited to non-durable consumption goods, the author supports this view for 26 out of 35 items.

\footnotetext{
4 Using a score gathering several parental inputs, the authors assess the cognitive stimulation and emotional support that children receive. However, they also show that parental inputs changes correlate to changes in various measures (both cognitive and non-cognitive) of child achievement.
} 
Usually, the literature relates an individual's educational choice to his economic outcomes. The primary reference model is the Card (1999)'s one where individuals choose years of education to maximise the present discounted value of future income flows. In the simplest version of the model, income flows are a function of education. Individuals are assumed to work a certain number of years which depends on years of schooling, enlightening a trade-off between individual education and labour supply. We sketch a simple model, modifying Card (1999), to show whether and the extent to which the number of the child's years of schooling impacts family's (non-durable) consumption when the family chooses the optimal amount of the child's education. In our setting, the offspring post-compulsory education is a co-decision between parents and the child. Then, our model adds to the literature the parents taking part in the decision process for two reasons that may coexist and complement each other. First, we assume an altruistic motive. Parents care about children future well-being. Since future children's well-being might depend on children's years of education, it is sensible that the family chooses the child's optimal years of schooling. Second, education can be an insurance device that may either complement or substitute precautionary saving. So far, the literature has emphasised that education is a multi-period investment whose return is uncertain, despite the ex ante commitment of resources and time (Levhari and Weiss (1974)). Against this uncertainty, households could at least partially insure their children through borrowing, saving and labour supply adjustments (Blundell et al. (2008); Low et al. (2010); Heathcote et al. (2014)). Here, we underline another mechanism that operates through the household permanent income component that depends on the child education. In Italy, wage returns to education are meagre compared to other European countries. However, wages are conditional on working. Education is a powerful tool to increase employment probability. Put it differently, one more year of education could reduce the probability of facing negative income shocks with a more continuous employment carrier. Compared to the counterfactual of not acquiring it, one more year of education for the child implies less future income uncertainty and less need for parents' financial help. This mechanism increases both child's and parents' permanent income, namely the household's permanent income. Family ties and altruism are important components of this mechanism, but we do not think they belong to Italian society only. For instance, we have already mentioned the UK statistics about a 46\% increase in young people aged 20-34 living with parents over the last two decades. Cohabitation in this respect is one of the possible ways to limit the child's financial distress.

Let $\mathrm{C}(\mathrm{S})$ denote the average level of consumption (per year) a family will receive if they acquire schooling level $\mathrm{S}$ for their child/children. Altruistic parents care about the child's current and future well-being. Assume that a risk-averse household chooses $\mathrm{S}$, the optimal schooling level of the child, to maximise a utility function $U(S, C)$, where

$$
U(S, C)=\ln (C)-h(S)
$$

and $h$ is some increasing convex function.

In theory, the function $h(S)$ could enter into Eq. 1 positively or negatively. In the former case, child's education is a normal consumption good. In the latter case, education is a costly production good (Lazear (1977)). Equation 1 implies that utility 
is intertemporally separable and that the instantaneous utility depends on the family consumption level (per adult equivalent). The child years of schooling enters into equation 1 in an additive separable way and is equal to zero if the child is not in postcompulsory education. This hypothesis of additive separability is crucial in our analysis from both a theoretical and empirical perspective. From a theoretical perspective, it allows us to follow Jappelli and Pistaferri (2006) and consider a flexible model specification of household consumption which builds on the assumption of a random walk in the data generation process of the family permanent income component and serially uncorrelated transitory income shocks:

$$
\ln C_{h, t}=\ln C_{h, t-1}+\phi\left(\frac{\lambda+r}{1+r} \epsilon_{h, t}-\lambda \epsilon_{h, t-1}+\psi_{h(S)}\right)
$$

where $\phi$ measures the extent to which consumption, at time $t$, responds to income shocks; $\lambda$ corresponds to the excess sensitivity of consumption to current and past transitory income; $\epsilon$ denotes transitory income shocks; and $\psi$ defines permanent income shocks that depend on the child education by assumption.

Child education impacts the family intertemporal budget constraints through its effect on the permanent household income. Then, family consumption level changes. Hence, we can write our Euler equation as Equation (2) nesting the three main consumption models. First, when households insurance from idiosyncratic shocks is complete, the parameter $\phi$ is equal to zero. In such a case, consumption is independent of income shocks. Second, $\phi$ is equal to 1 , and $\lambda$ is equal to 0 if the permanent income hypothesis holds. Third, the latter parameter is positive and equal to 1 in the rule of thumb model, according to which consumption is proportional to income. A value of $\lambda$ between 0 and 1 represents whether consumption responds to income over the amount warranted by the permanent income hypothesis. From an empirical perspective, the additive separability hypothesis of child education ensures a triangular structure and then an exclusion restriction necessary to implement both CF and IV methods in our empirical analysis.

Equation (2) amounts to saying that at any time $t$ (log of equivalent) consumption is given by past consumption level plus permanent and transitory income innovations. By recursive substitution, we obtain:

$$
\ln C_{h, t}=\phi \int_{i=0}^{t} \psi_{h(S)} d t+\phi\left(\frac{\lambda+r}{1+r} \epsilon_{h, t}-\lambda^{t-i} \epsilon_{h, t-1}\right)
$$

Averaging across time, under the assumptions that $t$ is sufficiently large and $\lambda$ is equal to zero, we obtain the following expression for consumption:

$$
\ln C_{h, t}=\phi \int_{i=0}^{t} \psi_{h(S)} d t
$$

Equation (4) states that the household consumption level is given by the sum of innovations in permanent family income from the beginning of each family member's 
working life to the current time t. The transitory component vanishes out even if it is not $i . i . d$ but serially correlated.

We can then rewrite Eq. 1:

$$
V\left(S, \psi_{h}(S)\right)=\ln \left(\psi_{h}(S)\right)-h(S)
$$

where this function generalises the discounted present value objective function when households discount future permanent income shocks at a rate $\mathrm{g}^{5}$, and child's schooling is measured in years:

$$
\int_{i=0}^{\infty} \psi(S) \exp (g t) d t=\psi(S) \frac{\exp (-g S)}{g}
$$

We assume that a raise in the child's schooling years increases the family positive income shocks shifting the household production function. Then, education is a production rather than a consumption good. In "Online Appendix A1", we show that our data support this hypothesis.

An optimal schooling choice satisfies the first-order condition:

$$
h^{\prime}(S)=\frac{\psi^{\prime}(S)}{\psi(S)}
$$

Assume now that a university reform exogenously changes higher education costs (keeping constant the costs for all the other educational levels). For a given household production function, this reform monotonically increases the optimal years of schooling. Indeed, the amount on the left-hand side of Eq. 7 reduces. In Fig. 1, this means that the optimal choice $S_{0}^{*}$ shifts to $S_{1}^{*}$. The exogenous change of the cost of higher education changes the slope of the indifference curve. The dotted indifference curve is now determining the new optimal choice. Since the child's optimal schooling increases, the household production function shifts upwards, increasing the (expected) positive permanent income shocks as illustrated in Fig. 1.

\subsection{The university reform}

The Bologna declaration's main objective, the so-called “Bologna process", signed by 30 European countries in 1999, was to harmonise the highly fragmented European university systems. A similar structure of the university degrees for standards and qualifications was required to foster and increase the mobility and employability of tertiary-educated individuals across the member states. The Bologna process introduced a two-tier university bachelor and master degrees system and the European Credit Transfer and Accumulation System (ECTS).

Before the reform, a binary one-tier system characterised the Italian tertiary education system. Individuals could choose between two paths, a Laurea or a university diploma, to earn a higher education degree. The former was more academic-oriented.

\footnotetext{
5 The discount factor $g$ depends upon the household's rate of time preference.
} 


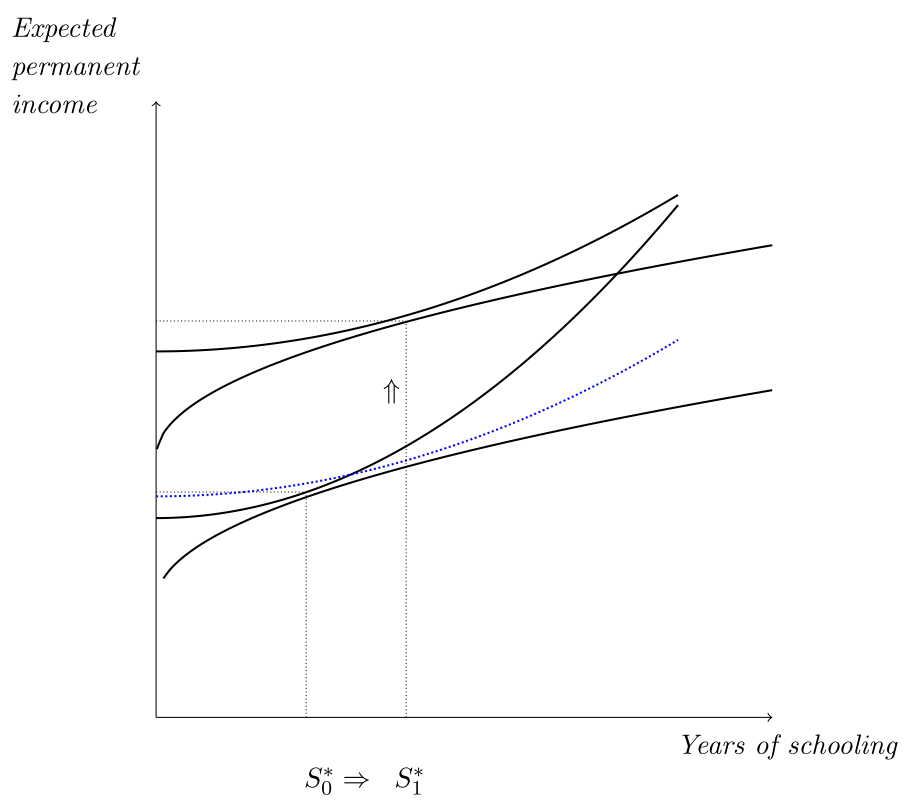

Fig. 1 Optimal choice of years of schooling

Its length depended upon the field of study from a four-to-six-year degree programme. It was the primary tertiary education qualification, at a social and academic level, mainly providing access to public sector careers and specific regulated occupations. Instead, the university diploma's nature was vocational since entering certain professions required it, e.g. nursing career. Its length varied from two to three years. Since its introduction in 1990, it has always had a minor role in the tertiary education choice compared to the more attractive Laurea degree. For instance, in 1998, only $11 \%$ of the high-school graduates enrolled in this type of degree (see also Cappellari and Lucifora 2009). Moreover, other distinguishing features characterised this pre-reform system. The university enrolment rates were low, the number of graduates was small, too many students were beyond the studies' legal duration, and the dropout rates were very high. ${ }^{6}$

To tackle all these issues, Ministerial Decree n.509/1999 introduced the Bologna process reform. In the academic year 2001-2002, all universities abolished the university diplomas and divided the former Laurea degree into two levels: a three-year degree, called Laurea Breve (i.e. bachelor degree), and an additional two-year degree, called Laurea Magistralis (i.e. master degree). The bachelor degree provides adequate knowledge of general scientific principles and specific professional skills. Students can now stop their higher education after three years but holding a university degree. The master course supplies advanced education and training for highly qualified pro-

\footnotetext{
${ }^{6}$ For instance, to name some stylised facts, we elaborated MIUR data from 1995 to 2000. First, $65 \%$ of high-school graduates enrolled at university. Seventeen per cent of the students were freshmen, and $24 \%$ dropped out after the first year. Per year, $8 \%$ of the students' population graduates. Finally, only $60 \%$ of enrollees graduated on time.
} 
fessions in specific sectors to those who decide to continue their academic studies after the bachelor degree. However, the reform allows the so-called Lauree a Ciclo unico, which still consists of a single-tier structure as, for instance, for Medicine and Surgery degree.

Besides, universities gain autonomy over teaching. They can set the student curriculum, the number of exams and their contents. Then, even within the same field, the existing Laurea degrees are pretty heterogeneous. However, the ECTS now precisely fix each exam's workload, whereas the previous regime did not impose any constraints.

In our empirical exercise, we exploit the variability generated by introducing this two-tier structure of university degrees. We expect that introducing a briefer degree, the smaller number of exams and their shorter contents make university attendance less costly. Besides, the university reform enters the model only through its effect on schooling years (the variable that it targets).

\section{Data, identification strategy and preliminary analysis}

\subsection{SHIW data}

We use the 1995-2006 waves of the Survey on Household Income and Wealth (SH I W) to estimate the model. The SHIW is a nationally representative household survey administered in Italy every two years by the Bank of Italy, collecting information on a sample of roughly 22,000 individuals and 8,000 households per wave. ${ }^{7}$ It has a repeated cross section structure with a panel element of about 50 per cent of the sample. SHIW, in addition to net income and demographics data, collects information about household consumption expenditures. To the best of our knowledge, this makes the SHIW the only representative large-scale Italian dataset to include both household net of taxes income, consumption, children's education status and family background indicators. The database allows us to consider only broad consumption categories classified as overall consumption, non-durable consumption goods and durable consumption goods. The definition of non-durable consumption goods includes all spending on both food and non-food consumption. ${ }^{8}$ Therefore, we cannot rule out the inclusion of tuition fees in this measure. Unfortunately, we cannot single out this item if present. However, we claim that it is not a big concern for our analysis for two reasons. First, the average tuition fees are not that high in Italy because they are mainly state-funded. For example, the 2006 OECD report shows that in the academic year 2003/04, they amounted to 983 USD. Second, no change in tuition fees took place to alter the consumption of treated individuals as opposed to the untreated ones.

We account for scale economies within the family, equalising these amounts with the household size's square root. We normalised them in terms of 2000 constant prices.

Our simple theoretical framework relates household consumption to child education. The outcome we look at in our main results is the log of adult equivalent

\footnotetext{
7 There is one exception to the two years rule. The 1998 survey was after the 1995 wave.

8 See the following website: https://www.bancaditalia.it/statistiche/tematiche/indagini-famiglie-imprese/ bilanci-famiglie/documentazione/index.html for further details.
} 
non-durable consumption expenditures. Focusing on non-durable consumption rather than the overall level shows that households vary their essential expenditures behaviour compared to the child's counterfactual world with one less education year. In doing so, indirectly, our analysis is consistent with Cappellari and Lucifora (2009)'s result that those most affected are individuals from the less advantaged parental background. However, we replicate the analysis using the log of adult equivalent consumption expenditures (i.e. the sum of non-durable and durable consumption expenditures) for consistency with our model. Differences in the impacts on these two consumption aggregates are minor (see "Online Appendix C1"). Hence, we also verify whether households adjust the non-durable versus durable consumption choice even if overall consumption is smoothing. ${ }^{9}$ Given these aggregate measures, a potential concern could be the genuine increase in consumption due to the additional costs the households need to face when their children start college. We do not think that this argument, even if it holds, harms our paper's narrative. Consider the two scenarios in the counterfactual world. First, the child with one less year of education does not work. In such a case, one less year of education reduces the employment probability confirming our model. Second, the child works, but her earnings current and future are lower than those predicted from one more year of education. This result is also in line with our model. It is unlikely that what we estimate is just an increase in college expenditures for two reasons. First, university fees are a transitory shock to income. Yet, in our model, the non-durable consumption level depends on permanent income shocks. Second, as we will show, the impacts are too moderate to suggest that they rely on the fees paid. However, with the data in our hands, we cannot corroborate further this statement.

Years of schooling of each child measures educational choices. In Italy, individuals aged five can enter the schooling system, although the statutory age is six. Very few individuals start schooling at this age. However, we can identify them by exploiting the information on the degree achieved at the interview time. If a child is still a student, we measure schooling years equal to the difference between the current age and six or five. If he/she is not, we measure them as the legal number of years to achieve the degree in his/her possession. For instance, an individual has thirteen years of schooling (i.e. five years in high school plus three years in lower secondary school plus five years in primary school) if he/she has a high-school diploma and is no longer in education. ${ }^{10}$

The data do not contain information on the school/university attended by the children. Students' mobility, however, is pretty low in Italy. Moreover, even if students enrol at a university located in a different city from their parental home, they do not change their residency. If they do, they lose economic benefits (i.e. more generous scholarships) recognised only to those living away from home. Then, as explained in the questionnaire, ${ }^{11}$ any members temporarily absent (e.g. away for study) are surveyed by the Bank of Italy as a component of the household. Hence, in our data,

\footnotetext{
9 A fraction of households only consume non-durable goods. Hence, to use this measure, we need an instrument to control the household selection process.

10 We impute an arbitrary value of three to the years of schooling of the very few (20) individuals who have declared to have any degree.

11 See the beginning of the section that records the composition of the family at the end of the survey year: https://www.bancaditalia.it/statistiche/tematiche/indagini-famiglie-imprese/bilanci-famiglie/ documentazione/index.html?com.dotmarketing.htmlpage.language=1.
} 
selection bias on co-residentially is negligible if it exists. Only $1.86 \%$ of individuals aged between 18 and 22 are not living with their parents. Conditioning on the educational status, the percentage of those who are not students and are not living with their parents corresponds to just $1.66 \%$.

\subsection{LoSai data}

To complement the analysis with a plot of a comparison of the employment probability and earnings per day worked of treated and untreated cohorts, we use administrative LoSai data from social security registers made available by the Italian Social Security Institute (INPS, Istituto Nazionale di Previdenza Sociale). ${ }^{12}$ Two workers' birth date randomises the sample covering 6.5 per cent of all individuals registered with INPS. We merge the archives of the individual employment histories in the salaried private sector, including semi-subordinate employees, all types of social security contributions paid, including self-employment and public administration, and unemployment benefit receipts. The data contain information on individual characteristics, excluding education. For that reason, we cannot estimate the wage return to education. We consider age profiles ten years after the 15-22 age interval of our primary analysis. We stop at 30 years to observe all cohorts treated and untreated (from 1976 to 1988) in the entire age interval of 25 to 30. Our data do not go beyond the year 2018. We assign treatment using the same rule applied in Table 1.

\subsection{Sample selection criteria and identification strategy}

Our analysis focuses on the post-compulsory schooling age (i.e. between fifteen and twenty-two years old) in 1995-2006. This criterion leaves us with 11,433 age/individuals observations. Given the children's age, we centre our data around 2002 , the threshold year for implementing the reform, and we cover an interval of -7 , +4 years. Table 1 shows how we assign the treatment indicator conditional on turning an age between 15 and 22 before and after introducing the reform. We underline the age/year of birth pair that we can observe since we do not have an annual dataset in bold.

Moreover, Fig. 2 displays the cohort of birth's treatment probability implied by our selection rule. We never (at any age between fifteen and twenty-two) assign treatment to all individuals born before 1980 . Hence, for them, the probability of being treated is zero (control group). We always (at each age between fifteen and twenty-two) assign treatment to all individuals born after 1985. Their treatment probability is equal to 1 (treatment group). For marginal cohorts born between 1980 and 1985, our instrument varies across cohorts given age and across ages given cohort of birth. Their treatment probability is, therefore, between zero and one. For instance, individuals born in 1982 represent the first cohort treated by the university reform at the most common age (19 in 2001) to access university. This cohort is untreated between fifteen and eighteen years of age (i.e. its treatment probability is zero in this age range). These marginal cohorts

\footnotetext{
12 Access to LoSai data is publicly available for research purposes by filling a form downloadable at https:// www.cliclavoro.gov.it/Barometro-Del-Lavoro/Pagine/Microdati-per-la-ricerca.aspx.
} 
Table 1 Identification strategy: treatment indicator

\begin{tabular}{|c|c|c|c|c|c|c|c|c|}
\hline \multirow[t]{2}{*}{ Year of birth } & \multicolumn{8}{|c|}{ Age } \\
\hline & 15 & 16 & 17 & 18 & 19 & 20 & 21 & 22 \\
\hline 1973 & - & - & - & - & - & - & - & $\mathbf{0}$ \\
\hline 1974 & - & - & - & - & - & - & $\mathbf{0}$ & 0 \\
\hline 1975 & - & - & - & - & - & $\mathbf{0}$ & 0 & 0 \\
\hline 1976 & - & - & - & - & $\mathbf{0}$ & 0 & 0 & $\mathbf{0}$ \\
\hline 1977 & - & - & - & $\mathbf{0}$ & 0 & 0 & $\mathbf{0}$ & 0 \\
\hline 1978 & - & - & $\mathbf{0}$ & 0 & 0 & $\mathbf{0}$ & 0 & $\mathbf{0}$ \\
\hline 1979 & - & $\mathbf{0}$ & 0 & 0 & $\mathbf{0}$ & 0 & $\mathbf{0}$ & 0 \\
\hline 1980 & $\mathbf{0}$ & 0 & 0 & $\mathbf{0}$ & 0 & $\mathbf{0}$ & 0 & $\mathbf{0}$ \\
\hline 1981 & 0 & 0 & $\mathbf{0}$ & 0 & $\mathbf{0}$ & 0 & $\mathbf{0}$ & 0 \\
\hline 1982 & 0 & $\mathbf{0}$ & 0 & $\mathbf{0}$ & 1 & 1 & 1 & 1 \\
\hline 1983 & $\mathbf{0}$ & 0 & $\mathbf{0}$ & 1 & 1 & 1 & 1 & 1 \\
\hline 1984 & 0 & $\mathbf{0}$ & 1 & 1 & 1 & 1 & 1 & 1 \\
\hline 1985 & $\mathbf{0}$ & 1 & 1 & 1 & 1 & 1 & 1 & 1 \\
\hline 1986 & 1 & 1 & 1 & 1 & 1 & 1 & 1 & 1 \\
\hline 1987 & 1 & 1 & 1 & 1 & 1 & 1 & 1 & 1 \\
\hline 1988 & 1 & 1 & 1 & 1 & 1 & 1 & 1 & 1 \\
\hline 1989 & 1 & 1 & 1 & 1 & 1 & 1 & 1 & 1 \\
\hline 1990 & 1 & 1 & 1 & 1 & 1 & 1 & 1 & 1 \\
\hline 1991 & 1 & 1 & 1 & 1 & 1 & 1 & 1 & 1 \\
\hline
\end{tabular}

Numbers in bold font are the age/year of birth pair that we can observe in our analysis since we do not have an annual dataset

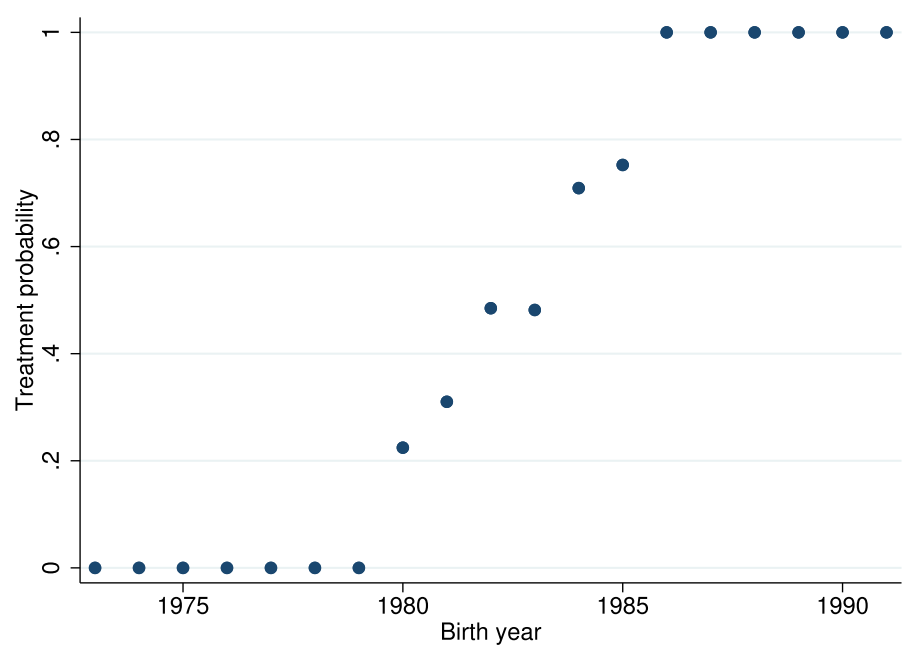

Fig. 2 Year of birth's treatment probability to the university reform

are in the control group for all those associated with a zero treatment probability and are otherwise in the treatment group. In other words, this cohort does not always belong 
to the treatment group because the staggering in the treatment is simply due to ageing. Then, we balance out three untreated cohorts with three treated cohorts for each age between fifteen and twenty-two. (Un)Treated individuals are those that reached the age (before) after the reform. However, at age 21 and 22, we cannot perfectly balance out the number of affected and unaffected cohorts because we consider potential treatment. For instance, individuals born in 1981 turned twenty-one at the time of the introduction of the reform. We assign a value of zero to our instrument to this cohort-age pair because potentially, in Italy, individuals aged twenty-one are already enrolled at university. Hence, we have four untreated cohorts and only two treated cohorts at this age. In the worst scenario, we are underestimating those exposed to the reform. Some of these individuals could have switched from the one-tier to the twotier university system. We are underestimating the exposure also of those not already enrolled at university at age twenty-one. However, if they were already enrolled at the previous university degree and proceeded in the old system, assigning them the unaffected status is correct. Our identification strategy relies on an instrument based on the child age/birth year combination. This combination constitutes our exclusion restriction that enters into the first stage regression model only. The reform does not introduce a randomised source of variation at the family level but an exogenous variation across a child's age and birth year. To compare households with similar observable characteristics, we cannot ignore considering some covariates.

Including child's birth cohort dummies, we exploit variation across child's ages as in a sole before and after setting. With the age dummies, we identify the effect by exploiting the variation across cohorts. We compare households with children of the same age born before and after to be treated by the reform. We exploit the staggering in ageing to consider time effects (i.e. time is perfect collinear to the inclusion of both age and cohort dummies) and the age profile of the reform's impact. We compare either the same family or different households observed at a different point in time. Since our instrument varies over time, we do not encounter collinearity problems in our first stage when we include the child's age, birth year and the treatment indicator.

Families with siblings in the 15-22 age range contribute cross sectionally to the identification by having an identical value for the adult equivalent non-durable consumption level and different years of schooling and treatment status for each child. They could also contribute through the panel structure if we observe at the same age the two siblings when one of them is treated, and the other is not. However, the SHIW structure of the data does not allow us to conduct a pure within-family analysis.

We can control for inequalities in living standards due to different parents' life cycle. We cut the lowest and the highest $5 \%$ of the distribution of the family head's age. Then, inequality in living standards across households is unrelated to the differences in these observed ages and changes in the population's age composition over time. Therefore, in our data, children in the narrow interval between fifteen and twenty-two have parents of a similar age. ${ }^{13}$ Finally, we cut the highest and the lowest $1 \%$ of the distribution of the permanent component of income innovations (see "Appendix A1") to reduce measurement errors in their estimates. Our final sample comprises 10,916 individuals living in families whose heads aged from 39 to 60 years old.

$\overline{13}$ The interquartile range of the age differentials lies between six and eight years. 
Table 2 Descriptive statistics

\begin{tabular}{|c|c|c|c|c|}
\hline & \multicolumn{2}{|c|}{ Overall sample } & \multicolumn{2}{|c|}{ Sample of those affected } \\
\hline & Mean & SD & Mean & SD \\
\hline Years of schooling & 11.41 & 2.49 & 11.57 & 2.44 \\
\hline Equivalent non-durable consumption (log) & 9.18 & 0.48 & 9.24 & 0.47 \\
\hline Missing income & 0.00 & 0.02 & 0.00 & 0.01 \\
\hline University reform & 0.39 & 0.49 & 0.90 & 0.30 \\
\hline Gender & 0.47 & 0.50 & 0.47 & 0.50 \\
\hline Siblings, (number) & 1.22 & 0.91 & 1.14 & 0.87 \\
\hline Hh age & 49.08 & 4.95 & 49.29 & 4.96 \\
\hline Hh education, (years) & 9.98 & 4.04 & 10.40 & 3.85 \\
\hline Both parents, (dummy) & 0.90 & 0.30 & 0.90 & 0.30 \\
\hline Sp education, (years) & 8.63 & 4.77 & 9.05 & 4.74 \\
\hline Sp missing education & 0.02 & 0.15 & 0.01 & 0.12 \\
\hline Hh missing education & 0.03 & 0.16 & 0.02 & 0.13 \\
\hline Permanent component income innovations & 0.06 & 0.08 & 0.07 & 0.08 \\
\hline Family educational background, (years) & 0.14 & 2.17 & 0.26 & 1.99 \\
\hline Hh missing family background education & 0.06 & 0.23 & 0.10 & 0.30 \\
\hline Hh missing family background occupation & 0.07 & 0.25 & 0.11 & 0.32 \\
\hline GDP per employee & 49.20 & 6.30 & 49.95 & 5.85 \\
\hline Unemployment rate & 0.11 & 0.06 & 0.09 & 0.05 \\
\hline Sample Size & 10,916 & & 4,672 & \\
\hline
\end{tabular}

Sources: SHIW, Bank of Italy, waves 1995-2006. Hh stands for Household Head; Sp indicates spouse. GDP per employee and unemployment rate are at regional level

Table 2 reports the means and standard deviations of the main variables for the entire sample and the sub-sample of treated cohorts. The two columns are pretty similar concerning observable characteristics, suggesting that the reform is exogenous. In "Online Appendix C1", we show that when we regress the treatment variable on the set of our observable characteristics (plus age and year of birth dummies), an $F$-test fails to reject the null hypothesis that the coefficients of these characteristics are jointly equal to zero. Hence, our treatment indicator is randomly assigned. Table 2 displays, on average, an increase in children's schooling attendance and a higher amount of non-durable consumption for post-reform cohorts.

\section{Empirical strategy}

\subsection{The model}

All the economic arguments posit for the endogeneity of the child years of schooling and household non-durable consumption. Hence, the $O L S$ estimates of the parameters $\beta_{a g e_{i t}}$ in the following model are biased and inconsistent: 


$$
\begin{aligned}
y_{1 h t}= & \alpha+\sum_{a=16}^{22} a \alpha_{a}+\sum_{j=1974}^{1991} c \theta_{j}+\sum_{q=2}^{5} q \delta_{q}+\left(\beta_{0}+\beta_{a g e_{i t}}\right) y_{2 i t} \\
& +\gamma_{0} X_{i}+\gamma_{1} X_{h}+\gamma_{2} X_{h t}+\gamma_{3} f_{h}+\gamma_{4} s_{h}+u_{1 h t}
\end{aligned}
$$

The household non-durable consumption for individual $i$ who was born in cohort $j$ and lives in household $h$ when aged $a$ at time $t$ is the dependent variable $y_{1 h t}$, and $y_{2 i t}$ denotes the endogenous variable, namely the child years of schooling. Here, $\beta_{0}+\beta_{\text {age }}$ it is the impact of child's schooling on household non-durable consumption at child's $a g e_{i t}$. We specify $\beta_{a g e_{i t}}$ to be a quadratic polynomial in $a g e_{i t}$ and $\beta_{0}$ to be a constant. Absent the university reform, the child's age cycle profile of treated and untreated household consumption would have been the same. There are two reasons for modelling this child's age profile. First, it feeds in marginal costs and benefits of household choices varying over the child age (see "Appendix B1" for more details on this issue.) Second, a keep up with the Joneses effect at ages lower than 19 could unfold. The reform induced some individuals to enrol at university who, in its absence, would have not. The reform introduced another degree recognised by the labour market to which the high-school diploma and the compulsory lower secondary degree might compare. Some individuals would have tried to achieve the high-school diploma to minimise the loss in the returns of having a lower education degree.

Affected and unaffected families have children of the same age who are born in contiguous cohorts. On average, these cohorts share similar characteristics but differ because of the exogenous treatment. To be sure to compare similar families, we have to include in our model some covariates. The matrix $X_{i}$ includes observable individual characteristics such as gender. The model considers age $\left(\alpha_{a}\right)$ and the cohort of birth $\left(\theta_{j}\right)$ dummies whose combination accounts for time fixed effects. We also control for dummies for the income quintile in which the household sits $\left(\delta_{q}\right)$. The matrix $X_{h t}$ includes the number of siblings, the age and age square of the head of the household, and a dummy for the spouse's presence. We approximate local market conditions using the regional GDP per employee, unemployment rate and dummies for the residency region. We account for the household's time-invariant observable characteristics in $X_{h}$, which contains the years of schooling of both parents (if the spouse is present, otherwise the head's education) and a dummy for missing information on family income.

Finally, we use a proxy for idiosyncratic household shocks of permanent income, $s_{h}$, and the unobservable characteristics related to the educational family background, $f_{h}$. We follow Björklund et al. (2012) to construct these measures. The variable $s_{h}$ is a proxy of $\psi_{h}(S)$ presented in our model. It is averaged over the family's time observations to smooth out excess variability since the panel dimension of the data is quite limited and, therefore, is time-invariant. ${ }^{14}$

$\overline{14}$ See Appendices A1 and A2 for further details. 
To deal with the endogeneity issue, we carry out a control function method. The first stage regression model amounts to estimate:

$$
y_{2 i t}=\left(\pi_{0}+\pi_{a g e_{i t}}\right) z_{i t}+\sum_{a=16}^{22} a \pi_{a}+\sum_{j=1974}^{1991} c \theta_{j}+\sum_{q=2}^{5} q \delta_{q}+\pi_{3} f_{h}+\pi_{4} s_{h}+v_{2 i t}
$$

For simplicity sake, we do not report other covariates in both Eqs. 8 and 9, but we include them in the empirical analysis. We allow the household idiosyncratic permanent income and family educational background shocks to shape the correlation between the error terms in Eqs. 8 and 9 under the assumption of mean independence from the instrument (see "Appendix B2" for details on the procedure applied).

Hence, the second stage regression model corresponds to:

$$
\begin{aligned}
y_{1 h t}= & \alpha+\sum_{a=16}^{22} a \alpha_{a}+\sum_{j=1974}^{1991} c \theta_{j}+\sum_{q=2}^{5} q \delta_{q}+\left(\beta_{0}+\bar{\beta}_{a g e_{i t}}\right) y_{2 i t} \\
& +\left(\beta_{0 v}+\beta_{\text {age }_{i t} \nu}\right) \nu_{2 i t}+\left(\gamma_{0}+\gamma_{a g e_{i t}}\right) \nu_{2 i t} y_{2 i t} \\
& +\left(\gamma_{1}+\gamma_{\text {age }_{i t}}\right) f_{h}+\left(\gamma_{2}+\gamma_{2 a g e_{i t}}\right) s_{h}+\left(\gamma_{3}+\gamma_{3 a g e_{i t}}\right) y_{2 i t} f_{h} \\
& +\left(\gamma_{4}+\gamma_{4 a g e_{i t}}\right) y_{2 i t} s_{h}+u_{1 h t}
\end{aligned}
$$

The linear combination of $\left(\beta_{0}+\bar{\beta}_{a g e_{i t}} * a g e_{i t}+\bar{\beta}_{a g e_{i t}}^{2} * a g e_{i t} * a g e_{i t}\right)$ measures the age-specific effect of one more year of schooling on the household non-durable consumption.

We perform the $C F$ method because it is more general but easily comparable to I $V(2 S L S)$. Although this is not an estimation of the structural model, this method allows us to estimate the impact of one more year of child schooling on household consumption. Instead, a sole reduced-form analysis would measure the reform's impact on child years of schooling and household consumption.

We exploit four properties of the control function method to identify our parameter (Blundell and Matzkin (2014)). First, the joint distribution of the reduced-form error terms of the child's schooling and household non-durable consumption equations is independent of the exogenous instrument. Second, these error terms enter additively into the reduced-form equations. Third, there is a correlation between the error terms in the child's years of schooling and household non-durable consumption equations at the heart of the endogeneity problem. Fourth, we exploit the exogenous variation generated by the university reform to have the exclusion restriction. The mean independence of $u_{1}$ from $y_{2}$ and $z$ conditional on $v_{2}$ is sufficient to identify the average treatment effect on the treated, ATT.

When the linear combination of $\left(\gamma_{0}+\gamma_{a g e_{i t}} * a g e_{i t}+\gamma_{a g e_{i t}}^{2} * a g e_{i t} * a g e_{i t}\right)$ is statistically equal to zero (and hence the linear combinations of $\left(\gamma_{3}+\gamma_{3 a g e_{i t}} * a g e_{i t}+\right.$ $\left.\gamma_{3 a g e_{i t}}^{2} * a g e_{i t} * a g e_{i t}\right)$ and $\left(\gamma_{4}+\gamma_{4 a g e_{i t}} * a g e_{i t}+\gamma_{4 a g e_{i t}}^{2} * a g e_{i t} * a g e_{i t}\right)$ are also statistically equal to zero), $C F$ and instrumental variable $I V$ are equivalent. The $I V$ conditions on fitted values of the endogenous regressor. $C F$ conditions on both the 
endogenous regressor and the error term from the first stage equation and their interaction. When the interaction term is statistically equal to zero, the linear combination of the endogenous regressor and the error term is equal to the fitted values. Moreover, Vytlacil (2002) shows that the LATE approach is as an application of a nonparametric version of the CF method (see for more details Blundell and Costa Dias (2009)).

In "Appendix B3", we also present a nonparametric analysis based on Huber and Mellace (2015) for two reasons. First, it provides support in favour of the validity of the $C F$ assumptions. Second, it provides evidence that education is a costly production good (Lazear (1977)). To sum up, the conditions require to achieve identification are the four properties of the control function method. Yet, a causal interpretation needs a counterfactual when viewed in terms of potential outcomes. To compare before and after the reform similar households, we include in our regression model some covariates. We further control the child's age profile to identify the counterfactual age profile in the absence of the reform. On average, households with a child treated by the reform would have experienced the same age profile of consumption of untreated families didn't the reform take place. Hence, we impose a parallel age trend assumption. Families with a child born in cohorts that are never observed to be treated do not contribute to the estimated impact other than by helping to identify effects of control variables, including the age profiles.

One last remark on the identification strategy. Our data cannot allow us to estimate the effect age by age. Hence, we exploit both the panel and cross section structure of our data. ${ }^{15}$ To clarify how it works, in this example, we abstract from the age-specific effect. Consider three families. We observe the first family both before and after the treatment. For this household, we can carry out fixed effects estimates comparing its outcomes before and after. The second (third) family is in the data only before (after) being treated. The pre-reform effect is a weighted average of the effect on the first and the second family, and the post-reform effect is a weighted average between the first and the third. The pre-post-difference is this pre-post-weighted average difference. That is what we are identifying. In this design, where the child's birth cohort plays the role of time, we allow the effect to vary over the child's age using a control function method. This example also explains where age and child's birth year dummies find themselves. They are an essential part of the identification strategy. We could not assign each family to the pre-post-treatment group in their absence. Hence, we select people 15-22 years old for two reasons. First, to control the child's age profile of the household decision process under the assumption of common age profiles across cohorts. Second, to exploit our identification strategy at the cell level distinguishing between age and cohorts effects. Households with siblings contribute to the estimates twice. First, cross sectionally, if their children are (un)treated at different ages. Second, the unbalanced panel structure allows one to compare two siblings at the same age; one could be affected while the other could not. When these two siblings observed at the same age are both (un)treated, we exploit the cross-sectional dimension of our identification strategy.

\footnotetext{
15 Our identification strategy resembles the one performed by Altonji and Zhong (2021). We are exploiting variability at age/birth year cell level to achieve identification. Altonji and Zhong (2021) control for fixed effects at the cell level (type of undergraduate/ type of graduate degree, in their case). In our case, this variability at the cell level is not constant over time.
} 


\section{Empirical analysis}

\subsection{First stage regression}

The first stage regression model consists of estimating Equation (8). We use a secondorder polynomial in age and income quintiles for our proxies of the educational family background's unobservable characteristics and the permanent income innovations component described in Section 4.1 and "Online Appendix A1 and A2". We cluster standard errors by a household indicator since we assume independence over families but allow for serial correlation within families. ${ }^{16}$ All standard errors are bootstrapped (1000 draws) given the presence of generated regressors.

Table 3 reports our first stage estimates using a second-order polynomial in age. The first three columns of the table compare the impact of the university reform on a child's years of schooling across different sets of covariates included in the model (the family background, i.e. permanent income and educational family background innovations; age and year of birth dummies, and local labour market indicators.). The second column points to the importance of conditioning on age and year of birth dummies, the two relevant dimensions that jointly define the instrument's exogenous variability. The table unravels how the effect of the university reform varies over child age. The coefficient goes from 0.09 at age 15 to 0.40 at age 22 . In our preferred model specification (column (3)), in the twenties, the impact is higher than the one reported in the first row and the third column of Table 3, (0.19) that is a weighted average effect. The increase in the children's years of schooling ranges from 0.16 to 0.40 when it is statistically different from zero. The size of the effect is not large. For instance, families with children born in cohorts treated by the reform at age 22 increased their child's years of schooling by about less than one year ( 0.40 year) compared to the untreated ones. The absence of any keep up with the Joneses effect is apparent. At least, we do not find any catching up at the conventional statistical level. The reform was unsuccessful in boosting post-compulsory education. The reform did not explicitly target this goal. However, those who stop at compulsory education could belong to families that are heavily liquidity constrained. This kind of reform is too mild to ease these constraints that have to be directly tackled. ${ }^{17}$

The impact of the permanent income innovations on the children's schooling years (panel (a) of Fig. 3) is not statistically significant. It is statically different from zero and negative in very few age-income cells at the highest income quintile. Hence, education is not a consumption good. If it is, these coefficients would be positive and statistically different from zero. Therefore, our empirical evidence supports the assumption that children's schooling years enter (negatively) the household lifetime

\footnotetext{
16 We have also clustered standard errors by a household indicator and the children's cohort of birth. Results are robust and are available upon request from the authors.

17 Access to post-compulsory education could bottleneck university enrolment. For example, in the schooling year $97 / 98$, about $13.26 \%$ of students enrolled in high-school drop after the first year, $9.10 \%$ after the second year, $9.18 \%$ after the third year $6.85 \%$ after the fourth year and $14.76 \%$ after the fifth year. These withdrawals factor in the children's household conditions, such as poor cultural backgrounds and financial constraints. Children of financially constrained parents are not in the high-school leavers' pool made of families with fewer liquidity constraints.
} 
Table 3 First stage regression

\begin{tabular}{|c|c|c|c|}
\hline & \multicolumn{3}{|c|}{ Years of schooling } \\
\hline & (1) & (2) & (3) \\
\hline \multirow[t]{2}{*}{ University reform } & $-0.14 * * *$ & $0.18 * *$ & $0.19 * * *$ \\
\hline & $(0.05)$ & $(0.07)$ & $(0.07)$ \\
\hline$F$-test & 7.462 & 5.893 & 6.668 \\
\hline \multicolumn{4}{|l|}{ Age: 15} \\
\hline \multirow[t]{2}{*}{ University reform } & $-1.718^{* * *}$ & 0.055 & 0.090 \\
\hline & 0.069 & 0.096 & 0.107 \\
\hline \multicolumn{4}{|l|}{ Age: 16} \\
\hline \multirow[t]{2}{*}{ University reform } & $-1.164^{* * *}$ & 0.044 & 0.080 \\
\hline & 0.045 & 0.079 & 0.083 \\
\hline \multicolumn{4}{|l|}{ Age: 17} \\
\hline \multirow[t]{2}{*}{ University reform } & $-0.659^{* * *}$ & 0.053 & 0.089 \\
\hline & 0.045 & 0.079 & 0.079 \\
\hline \multicolumn{4}{|l|}{ Age: 18} \\
\hline \multirow[t]{2}{*}{ University reform } & $-0.205^{* * *}$ & 0.081 & 0.115 \\
\hline & 0.051 & 0.082 & 0.083 \\
\hline \multicolumn{4}{|l|}{ Age: 19} \\
\hline \multirow[t]{2}{*}{ University reform } & $0.200^{* * *}$ & 0.130 & $0.160^{*}$ \\
\hline & 0.056 & 0.082 & 0.089 \\
\hline \multicolumn{4}{|l|}{ Age: 20} \\
\hline \multirow{2}{*}{ University reform } & $0.555^{* * *}$ & $0.197^{* *}$ & $0.223^{* *}$ \\
\hline & 0.064 & 0.085 & 0.098 \\
\hline \multicolumn{4}{|l|}{ Age: 21} \\
\hline \multirow[t]{2}{*}{ University reform } & $0.860^{* * *}$ & $0.285^{* * *}$ & $0.304^{* *}$ \\
\hline & 0.088 & 0.103 & 0.120 \\
\hline \multicolumn{4}{|l|}{ Age: 22} \\
\hline \multirow[t]{2}{*}{ University reform } & $1.115^{* * *}$ & $0.393^{* * *}$ & $0.403^{* *}$ \\
\hline & 0.130 & 0.146 & 0.162 \\
\hline Family background & Yes & Yes & Yes \\
\hline Age and Cohort dummies & No & Yes & Yes \\
\hline Local labour market controls & No & No & Yes \\
\hline
\end{tabular}

We include as further regressors individual's, household's characteristics and income quintiles. Bootstrapped standard errors (1000 draws).

utility function in an additive separable way. It is consistent with Lazear (1977)'s main conclusions. Moreover, education is costly, implying that the amount of children's years of schooling chosen is lower than the wealth-maximising level because of its costs, including the opportunity costs measured by the foregone wage.

The effect of the innovations related to the educational family background (panel (b) of Fig. 3) is precisely estimated and varies across both the age and income quintile dimensions. One standard deviation increase in these innovations changes the child's 


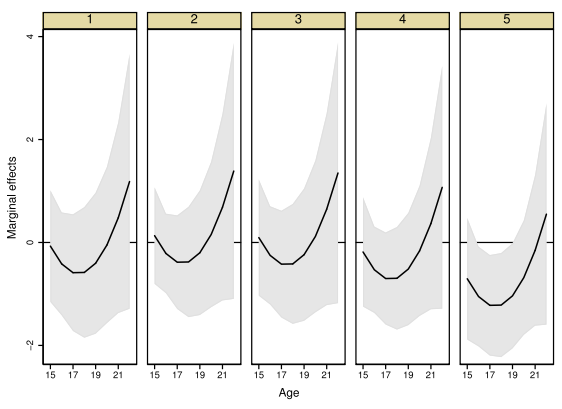

(a) Permanent component of income innovations

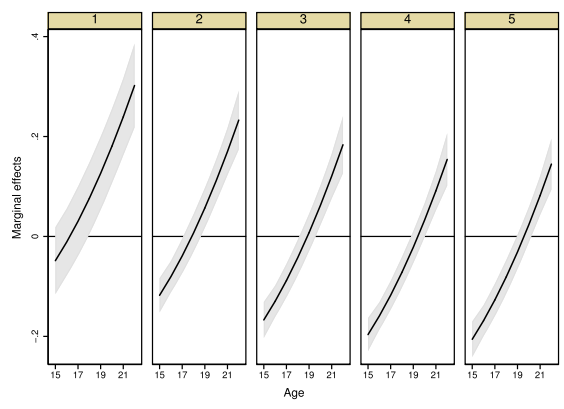

(b) Unobservable characteristics related to the educational family background

Fig. 3 First stage regression model. Notes Marginal effect of the unobservable characteristics related to the family educational background and the permanent component of income innovations on years of schooling. These marginal effects are estimated using a flexible parametric model specification across ages and income quintiles, second-order polynomial, for the unobservable characteristics related to the family educational background and the permanent component of income innovations). We include as further regressors individual's and household's characteristics, local market conditions proxied by regional variables, income quintile, age and year of birth dummies. Bootstrapped standard errors (1000 draws) and confidence bands at $95 \%$ level.

years of schooling in a range of -0.05 , at age 15 , and 0.30 years, at age 22 , in the lowest income quintile. This impact varies from -0.21 (at age 15) to 0.15 (at age 22) in the highest income quintile. Having grandparents with more years of schooling generates shocks that positively affect the child years of schooling when the expected marginal returns are higher (i.e. the impact is increasing in age and education level). We interpret this evidence as a further suggestion that education is costly. At the lowest income quintile, where recovering to precautionary savings against shocks is limited, these innovations' effect is either statistically equal to zero (at ages fifteen and sixteen) or positive. Hence, family background transfers traits, skills and preferences, which contribute to improving the future employment prospect (and increasing the future wage) of the offspring and making education an insurance device against future income shocks.

\subsection{Main regressions}

We consider the $O L S$ estimates as a benchmark, reported in the first column of Table 4. We account for the endogeneity of the years of schooling using the $I V$ estimator, second column, and the $C F$ estimator, third column, which is our method of reference. Under this latter setting, the degree of the model's endogeneity depends upon the correlation in the error terms of the child's years of schooling and household non-durable consumption equations as described in "Appendix B2". We also introduce the proxies for the family innovations in permanent income and the family educational background in the error structure using a second-order polynomial in age and income quintiles. 
Table 4 Main regressions

\begin{tabular}{llll}
\hline & OLS & IV & CF \\
\hline Age: 15 & & & \\
Years of schooling & $0.039^{* * *}$ & $0.264^{* *}$ & $0.300^{* * *}$ \\
& 0.012 & 0.125 & 0.107
\end{tabular}

Age: 16

Years of schooling

$0.029^{* * *}$
0.008

$0.270^{* *}$

$0.301^{* * *}$

Age: 17

Years of schooling

$0.021^{* * *}$

$0.275^{* *}$

$0.301^{* * *}$

0.005

0.125

0.107

Age: 18

Years of schooling

$0.016^{* * *}$

$0.279^{* *}$

$0.300^{* * *}$

0.003

0.125

0.107

Age: 19

Years of schooling

$0.014^{* * *}$

$0.282^{* *}$

$0.299^{* * *}$

0.003

0.125

0.107

Age: 20

Years of schooling

$0.013^{* * *}$
0.002

$0.284^{* *}$

$0.297^{* * *}$

Age: 21

Years of schooling

$0.015^{\text {*** }}$
0.002

$0.285^{* *}$

$0.295^{* * *}$

Age: 22

Years of schooling

$0.020^{* * *}$
0.003

$0.285^{* *}$

$0.293^{* * *}$

0.124

0.107

\begin{abstract}
Average effects of one more year of schooling on non-durable consumption. These effects are estimated using a flexible parametric model specification across ages (second-order polynomial) and using a second-order polynomial across ages and income quintiles for the unobservable characteristics related to the family educational background and the permanent component of income innovations. We include as further regressors individual's and household's characteristics, local market conditions proxied by regional variables, income quintile, age and year of birth dummies. Bootstrapped standard errors (1000 draws)
\end{abstract}

This model specification is the most accepted by our data in terms of the goodness of fit statistics and balances out the trade-off between flexibility and parsimoniousness. ${ }^{18}$

All the estimators retrieve a positive, statistically significant, average marginal effect of one more year of schooling on non-durable consumption. The comparison of the coefficients reveals a downward bias of the $O L S$ to the $C F$ parameter. The child's year of schooling negatively correlates with the residuals in the $O L S$ model regression. One possible interpretation is that those families who have a higher preference for today

\footnotetext{
$\overline{18}$ We have also carried out other functional form specifications of the error structure. Results are robust.
} 
consumption are less future-oriented and could opt out for a lower level of education. This time preference correlates to the child's abilities which affect the marginal costs and benefits of schooling. Since the university reform increased the child years of schooling, a smaller $I V$ coefficient to $C F$ suggests a negative correlation between time preference and expected marginal benefits (net of costs). In general, the $O L S$ tends to understate the effect of a child's years of schooling on household consumption because of the adverse selection into the schooling of low-consumption (possibly lowincome) families.

The OLS estimates' endogeneity bias is huge, while the difference between the $C F$ and the $I V$ parameters is small and negligible. The size of the effect differs across the estimation procedures ranging from 0.04 at age 15 to 0.02 at age $22(O L S)$, from 0.28 at age 15 to 0.30 at age $22(I V)$, and in a range of $(0.30,0.31)(C F)$. One could argue that our results fail to reveal an age-varying effect. We claim that this is not the case. Abstract now from this age-varying effect, and the correlation of the error terms in Eqs. 8 and 9 considering a standard $I V$ that identifies a Local Average Treatment Effect ( $L A T E$ ). In such a case, the $L A T E$ coefficient is the ratio between two coefficients: the reduced-form one at the numerator and the first stage coefficient at the denominator. ${ }^{19}$ In our estimates, this ratio amounts to 0.157 , which is equal to (0.03, see Table D1 in "Online Appendix D", divided by 0.19 , see Table 3 in the main text). Not surprisingly, this quantity approximates what we estimate as $I V$ under the hypothesis of an age-invariant effect (see Table F4 in the "Online Appendix"). This effect is not statistically different from zero because standard errors are pretty large. Under this age-invariant effect assumption, control function estimates are slightly higher 0.23 , but estimates are not precise. These quantities estimate an average of the child's age-specific impacts weighted by the sample distribution of the child's age for those treated by the reform. What seems an age-invariant impact in Table 4 stems from an age-varying first stage and reduced-form coefficients. Our estimated coefficients are not the age-specific ratios between the reduced-form and the first stage coefficients. Yet, they relate to these ratios. Hence, reported coefficients in Table 4 come from the combination of child-age profiles in the household consumption and child's years of schooling induced by the reform. Table 4's uncovered pattern is robust to changing the age window of our sample. For instance, we exclude ages 15 to 18, or we include ages 23 and 24. Moreover, we can show that a more parsimonious specification produces the same age-varying impacts. We report all these findings in "Online Appendix E". In this Online Appendix, we also report fixed-effects estimates. Our dataset is an unbalanced panel with a high attrition rate. For this reason, we prefer to resort to an age/year of birth cell identification strategy rather than a fixed-effects estimator that considers only families who are observed before and after the reform and then at different ages of the same child. Nevertheless, looking at Tables E12 and E13, we can argue that results are robust. When we assume the age-invariant effect, fixed effects and $I V-F E$ are downward bias towards $O L S$. Hence, the age-invariant impact puts more weight on families with a lower consumption level (and then permanent income) who changed the number of their child's years of schooling.

\footnotetext{
19 The reduced-form regression model amounts here to regressing the outcome variable, i.e. the non-durable consumption expenditures, on the instrument plus all the other control variables.
} 
Table 5 Confidence intervals robust to weak instruments

\begin{tabular}{ll}
\hline Test & $95 \%$ Confidence set \\
\hline AR & {$[.003104, .840543]$} \\
Wald & {$[-.043637, .341975]$} \\
\hline
\end{tabular}

We discuss two further technical issues before concluding our presentation of the main results. First, standard errors are pretty stable and do not differ much between the first and second stage regression models. However, they are not very small because of our sample size. Since estimated coefficients are higher in the second stage of the analysis for ages below 20, coefficients turn out to be statistically different from zero. As a final issue, we consider the instrument's weakness as suggested by the first stage's small $F$-test (see Table 2). We correct the confidence intervals bootstrapped standard errors, which are unreliable when the instrument is weak, and the degree of endogeneity is high. In such a case, the approximation of the normal distribution to the Wald-statistic distribution is not reliable. One can infer the parameter indirectly by testing the restrictions on the reduced-form coefficients imposed by the underlying relationship between the two-stage and reduced-form parameters. Under the control function method, we can obtain the reduced-form regression model by substituting Equation (8) into (9). However, the difference between the $I V$ and $C F$ estimates is slight. We compute the two-step identification-robust confidence sets for instrumental-variable (IV) estimation using a linear model under the homogeneous coefficient assumption. Hence, here we are bounding one coefficient. This choice is the most straightforward pathway to follow to show that our estimates lie in the robust confidence sets for two reasons. First, under this assumption, we can implement the official Stata command, twostepweakiv. The two-step identification-robust confidence sets are based on Andrews (2018), and the test corresponds to the minimum distance versions of the Anderson and Rubin (1949) (AR). Second, we know from the previous analysis that the homogeneous coefficient is downward biased compared to the agespecific coefficients because it fails to control the common age profile. Moreover, it is also less precisely estimated. If our coefficients lie within the confidence sets defined using the twostepweakiv, they might also be included in the age-specific confidence sets. Table 5 displays the statistic, including the standard Wald test that is not robust to weak instruments.

The $95 \%$ confidence intervals, calculated using the AR test, do not contain the zero, while the Wald 95\% confidence intervals do. However, the former confidence intervals are more reliable and contain our coefficients presented in Table 3.

Is the estimated parameter a reliable quantity? One could argue that $30 \%$ increase in the household's non-durable consumption per year of schooling is considerable. The private returns' entails roughly $10 \%$ increase in earnings per additional year of education. To show that our parameter is a reliable quantity, we proceed in two steps. First, we establish how far are our reduced-form estimates of the reform's impact from raw data. The difference between non-durable consumption of treated and similar untreated households is about $0.11 \log$ points in the raw data. After estimating the reduced-form model, we retrieve almost the same quantity, about 0.09, (averaging 
across significant effect only). We present these estimates in "Appendix D1". This slight difference reassures that the parametric model specification does not lead our results.

Second, we run placebo estimates using the SHIW data for the waves from 1993 up to 2000 . We counterfactually assume the existence of a reform of the tertiary education system in the year 1998. We replicate our analysis comparing household non-durable consumption of two untreated and two treated cohorts. Individuals born in 1993 and 1995 are untreated. Those born in 1998 and 2000 belong to the treated group. We report these estimates in "Appendix D2". The $I V$ and the $C F$ estimates of the impact of child years of schooling on household non-durable consumption are not statistically different from zero. The $O L S$ estimates are statistically significant and similar to the $O L S$ regression reported in Table 3 . Hence, our placebo analysis confirms the high degree of endogeneity characterising the relationship between child education and household (non-durable) consumption level. However, it does not find any effect of one more year of child education on family non-durable consumption when we control this endogeneity.

These two steps support the statistical reliability of our estimates. Which are their economic implications? To discuss this issue, we have to step back to our age-varying first stage regression estimates. Age by age, these estimates quantify the difference in the average years of schooling between individuals in treated cohorts and untreated ones. Our estimated coefficients are not large ranging from 0.09 to 0.40 years, and are in line with the literature. Malamud and Pop-Eleches (2010) leverage a 1973 Romanian educational reform, and about 0.8 years is what they find. This quantity measures the increased number of years of schooling in general rather than vocational education of treated cohorts compared to the untreated ones.

We cannot make a direct comparison with the empirical works on the returns to education. We do not have the data to prove it, but our second stage estimates can be consistent with private returns to education in line with this literature. We can also cast light on the size of our estimates from a different perspective. The permanent income hypothesis suggests that households revise non-durable consumption one-toone with permanent income shocks. Jappelli and Pistaferri (2020), starting from this assumption, show that families adjust their target wealth one-to-one after a permanent income shock. Our findings suggest that households revise their consumption by 0.30 after an income shock due to one more year of the child's education. If we compare it to 1 , the proportion related to other income shocks, this quantity does not appear to be a large number.

The shortage of evidence on age-specific effects in the private returns to education complicates our comparison. Yet, considering the child's age profile is an important challenge because the returns of one more year of education at 15 cannot be the same as those at 22. When we allow age-varying effects, we take into account differential returns at the education degree level. We would lose this relevant dimension with age-invariant effects. On the same token, the reduced-form analysis of the impact of the reform on household consumption cannot be child's age-invariant. The extent to which education can be an insurance device against adverse income shocks increases with the child's education level. This mechanism rises with the child's age. But, it is not the only mechanism at work. Consider those families whom child withdraw from 


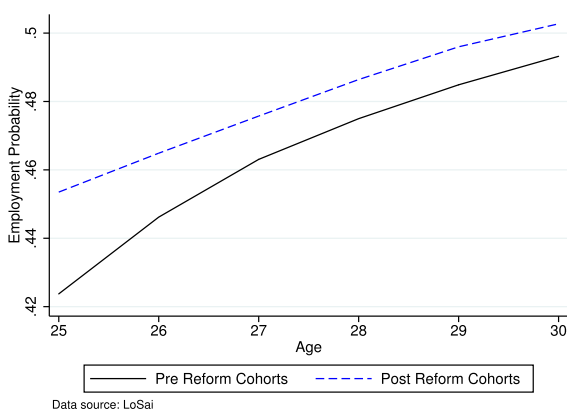

(a) Employment Probability

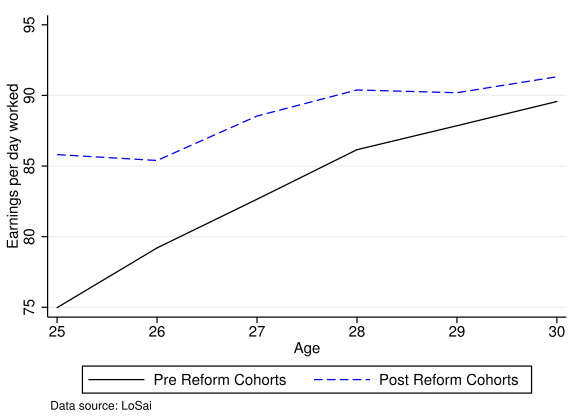

(b) Earnings per day worked

Fig. 4 Age profiles on labour market outcomes

school just after completing compulsory education. These households are more likely to be disadvantaged and with low incomes. For them, even a slight reduction in the probability of facing adverse income shocks could turn out to be a larger increase in consumption than what is experienced by less financially constrained households. The less likely the household is to be highly financially constrained: the higher the child's probability of one more year of education as we depart from the compulsory schooling age, the lower the increase in the insurance against income shocks. The combination of these processes leads to our coefficients that, at first sight, might seem age-invariant. Instead, they come out from considering the child's age profile that shapes the household decisions.

One last remark on this issue. What we estimate is different from the pure anticipation of the child's future private returns to education. This paper is a first step to estimate how families internalise the lower lifetime probability of adverse income shocks when their child acquire more education. Even though we interpret our estimated coefficient as the impact of one more year of schooling on household (non-durable) consumption, the reform was well far off to lead to an average of one more year of education of treated cohorts compared to the untreated ones. Hence, on average, treated families benefited less than $30 \%$ rise in consumption compared to their untreated counterparts. Our estimates are then consistent with what we observe in the data. The take-home message from a policy perspective is clear. Education can be an insurance device against adverse permanent income shocks.

Is the mechanism of a shift in the expected production function credible? Our data do not allow us to observe treated and untreated children in the labour market to verify whether the family expectation of lower adverse permanent income shocks is rational and credible. We use LoSai data to complement our empirical evidence plotting the age profiles from 25 to 30 of treated and untreated cohorts (from 1976 to 1988) of the employment probability and the earnings per day worked. We assign the individual treatment status based on birth cohort following the same rules described in Table 1. Earnings take the value zero if the individuals are not working. 
Figure 4 confirms our interpretation of the mechanism driving the results described in our simple model. Treated cohorts have a higher employment probability, benefiting; therefore, higher earnings per day worked on average.

We conclude that one more year of schooling of the child boosts household non-durable consumption. This result has important policy implications. Successful university system reform affects individuals' human capital and has an unintended positive effect on family consumption. In particular, a university reform that changes the marginal costs of higher education exogenously manipulates the child years of schooling. This exogenous variation raises the lifetime income of the household. Through this mechanism, household (non-durable) consumption increases. Education can be an insurance device against adverse permanent income shocks.

\section{Conclusions}

This paper studies the importance of children's schooling years on households' (nondurable) consumption decisions. We develop a framework where education is costly, entering negatively into the lifetime household utility function. This assumption means education to be a production rather than a consumption good (Lazear 1977). In this setting, the number of children's years of schooling chosen is lower than the wealthmaximising level because of its costs. We present a simple model to illustrate how, in 2001, a policy reform induced an exogenous shock of the household expected permanent income innovations. This reform introduced a two-tier structure of the university degree programme reducing the marginal costs of higher education. The most proximate consequences of this policy for a family were the increase in children's schooling years. Consistently with our model, household non-durable consumption raised. Our evidence on this is robust. We complement our empirical evidence with labour market outcomes of treated compared to untreated cohorts. These plots confirm that households can rationally internalise the lower probability of adverse income shocks when their child acquires more education. In brief, an exogenous shock in the offspring's schooling years raises family (non-durable) consumption instead of impacting the consumption bundle's composition. A reform of the university system that achieves its goal increases individuals' human capital and boosts consumption. Family behaviour is a relevant factor for the passthrough of education policies, and welfare analysis might consider it.

Supplementary Information The online version contains supplementary material available at https://doi. org/10.1007/s00181-021-02184-3.

\section{Declarations}

Conflict of interest The authors declare that they have no conflict of interest.

Open Access This article is licensed under a Creative Commons Attribution 4.0 International License, which permits use, sharing, adaptation, distribution and reproduction in any medium or format, as long as you give appropriate credit to the original author(s) and the source, provide a link to the Creative Commons licence, 
and indicate if changes were made. The images or other third party material in this article are included in the article's Creative Commons licence, unless indicated otherwise in a credit line to the material. If material is not included in the article's Creative Commons licence and your intended use is not permitted by statutory regulation or exceeds the permitted use, you will need to obtain permission directly from the copyright holder. To view a copy of this licence, visit http://creativecommons.org/licenses/by/4.0/.

\section{References}

Altonji JG, Zhong L (2021) The labor market returns to advanced degrees. J Law Econ 39(2):303-360

Anderson TW, Rubin H (1949) Estimators of the parameters of a single equation in a complete set of stochastic equations. Ann Math Stat 21:570-582

Andrews I (2018) Valid two-step identification-robust confidence sets for GMM. Rev Econ Stat 100(2):337348

Billari FC, Tabellini G (2010) Italians are late: Does it matter? University of Chicago Press, pp 371-412

Björklund A, Jäntti M, Roemer J (2012) Equality of opportunity and the distribution of long-run income in Sweden. Soc Choice Welfare 39(2):675-696

Blundell R, Costa Dias M (2009) Alternative approaches to evaluation in empirical microeconomics. J Hum Resource 44(3): 1

Blundell R, Matzkin RL (2014) Control functions in nonseparable simultaneous equations models. Quant Econ 5(2):271-295

Blundell R, Pistaferri L, Preston I (2008) Consumption inequality and partial insurance. Am Econ Rev 98(5):1887-1921

Bondonio D, Berton F (2018) The impact of degree duration on higher education participation: evidence from a large-scale natural experiment. Oxford Bull Econ Stat 80(5):905-930

Cameron SV, Heckman J (2001) The dynamics of educational attainment for black, hispanic, and white males. J Polit Econ 109:455-499

Cameron SV, Taber C (2004) Estimation of educational borrowing constraints using returns to schooling. J Polit Econ 112(1):132-182

Cappellari L, Lucifora C (2009) The "Bologna process" and college enrolment decisions. Labour Econ 16:638-647

Card D (1999) Chapter 30 the causal effect of education on earnings. In: Ashenfelter OC, Card D (eds) Handbook of labor economics, vol 3, Part A of Handbook of Labor Economics. Elsevier, pp 1801-1863

Cardoso AR, Portela M, Sà C, Alexandre F (2008) Demand for higher education programs: the impact of the bologna process. CESifo Econ Stud 54(2):229-247

Carneiro P, Ginja R (2016) Partial insurance and investments in children. Econ J 126(596):F66-F95

Carneiro P, Salvanes K, Tominey E (2016) Family income shocks and adolescent human capital. Mimeo

D'Hombres B (2007) The Impact of university reforms on dropout rates and students' status: evidence from Italy. JRC Scientific and Technical Reports 40507, European Commission, Joint Research Centre

Di Pietro G, Cutillo A (2008) Degree flexibility and university drop-out: the Italian experience. Econ Educ Rev 27(5):546-555

Grossman M (2006) Education and Nonmarket Outcomes, Vol. 1 of Handbook of the Economics of Education. Elsevier, chapter 10:577-633

Hahm S, Kluve J (2019) Better with bologna? Tertiary education reform and student outcomes. Educ Econ 27(4):425-449

Hai R, Heckman J (2017) Inequality in human capital and endogenous credit constraints. Rev Econ Dyn 25:4-36

Heathcote J, Storesletten K, Violante GL (2014) Consumption and labor supply with partial insurance: an analytical framework. Am Econ Rev 104(7):1-52

Huber M, Mellace G (2015) Testing instrument validity for late identification based on inequality moment constraints. Rev Econ Stat 97(2):398-411

Jappelli T, Pistaferri L (2006) Intertemporal choice and consumption mobility. J Eur Econ Assoc 4(1):75115

Jappelli T, Pistaferri L (2020) Permanent income shocks, target wealth, and the wealth gap. Csef working papers, Centre for Studies in Economics and Finance (CSEF), University of Naples, Italy 
Keane MP, Wolpin KI (2001) The effect of parental transfers and borrowing constraints on educational attainment. Int Econ Rev 42(4):1051-1103

Lazear E (1977) Education: consumption or production? J Polit Econ 85(3):569-598

Levhari D, Weiss Y (1974) The effect of risk on the investment in human capital. Am Econ Rev 64(6):950963

Low H, Meghir C, Pistaferri L (2010) Wage risk and employment risk over the life cycle. Am Econ Rev 100(4):1432-1467

Malamud O, Pop-Eleches C (2010) General education versus vocational training: evidence from an economy in transition. Rev Econ Stat 92(1):43-60

Manacorda M, Moretti E (2006) Why do most italian youths live with their parents? Intergenerational transfers and household structure. J Eur Econ Assoc 4(4):800-829

Mazzucco S, Mencarini L, Rettaroli R (2007) La transizione allo stato adulto (TSA) di due coorti di giovani italiani. Sociologia e politiche sociali 2:35-57

Michael R (1972) The effect of education on efficiency in consumption, Vol. An Empirical Test: The 1960 BLS Consumer Expenditures Survey. NBER 4:33-52

Michael R (1973) Education in nonmarket production. J Polit Econ 81(2):306-327

Vytlacil E (2002) Independence, monotonicity, and latent index models: an equivalence result. Econometrica 70(1):331-341

Publisher's Note Springer Nature remains neutral with regard to jurisdictional claims in published maps and institutional affiliations. 